\title{
Non-medicine Methods of Treatment of Gastroesophageal Reflux Disease
}

\author{
Matanat Efendiyeva \\ National Institute of Sport Medicine and Rehabilitation, Baku, Azerbaijan
}

Email address:

emt12@mail.ru

\section{To cite this article:}

Matanat Efendiyeva. Non-medicine Methods of Treatment of Gastroesophageal Reflux Disease. International Journal of Gastroenterology. Vol. 5, No. 1, 2021, pp. 33-39. doi: 10.11648/j.ijg.20210501.15

Received: December 20, 2020; Accepted: April 30, 2021; Published: May 21, 2021

\begin{abstract}
Few decades away a problem of throwing of acidic gastric content into an esophagus was reduced to the concept of reflux-esophagitis. In-depth study of pathogenesis of a disease resulted in "gastroesophageal reflux disease" (GERD) term which is acknowledged as leading disease of digestive system in terms of frequency and dangerous complications. GERD formation is determined by influence of numerous factors, however, it is generally accepted, that it is mainly related to insufficiency of lower esophageal sphincter (LES). Also, role of vasoactive intestinal peptide (VIP) in regulation of functional state of LES is determined. In spite of success in field of pharmacology, number of GERD patients has no downward trend which mainstreams search for non-medicine treatment methods. Physical factors affecting pathological processes by influencing regulatory processes are among these methods. Goal of this study is elaboration, scientific justification and clinical implementation of natural and preformed physical factors and acupuncture in treatment of patients with gastroesophageal reflux disease. Materials and Investigation methods: Randomized placebo-controlled study included 137 patients with gastroesophageal reflux disease, 63 (46\%) men and 74 (54\%) women, at the age of 18 to 65. Investigation included patients with no contraindications for physiotherapy. Patients with Barrett's esophagus, stricture of esophagus, esophagus ulcer have also been excluded from investigation. Patients were divided into 3 groups: Ist group - 40 GERD patients, including high-frequency electromagnetic field effect and general iodine bromine bathes. II nd group - 67 GERD patients passing acupuncture treatment course. Control group was comprised of 30 GERD patients, receiving placebo MEF therapy. Treatment was carried out without medicines. Therapeutic effectiveness of complex influence of microwave electromagnetic field therapy (MEF-therapy) applied to collar area alternated with general iodine-bromine bathes on clinical manifestations of GERD is determined. Treatment course contributed to reliable decrease of increased count of VIP - a neurotransmitter, regulating LES tonus. In term, it contributed to improve of functional state of LES, reliable decrease of reflux index, and, as a result, improvement of clinical and functional indicators. Estimation of clinical manifestations of a disease among patients of $2^{\text {nd }}$ group displayed positive dynamics of clinical and functional indicators. Round-clock $\mathrm{pH}$-monitoring of stomach and esophageal content shows reliable decreaseof transitory relaxations of LES during single acupuncture procedure and increase of $\mathrm{pH}$ of gastric content. Acupuncture course also resulted in decrease of elevated VIP numbers.
\end{abstract}

Keywords: Gastroesophageal Reflux Disease, pH-Metry, Microwave Electromagnetic Field Therapy (MEF-Therapy), General Iodine Bromine Bathes, Acupuncture, Vasoactive Intestinal Peptide

\section{Introduction}

Gastroesophageal reflux disease (GERD) holds leading position in a structure of gastroenterologic incidences. Main symptom of GERD is a burp, registered among $20-40 \%$ of adult population [1-4].

GERD is a polysymptom disease, conditioned by damage of an esophagus and adjacent organs as a result of initial disorder of motor function of esophagus, weakening of anti-reflux barrier of a lower esophageal sphincter, decrease of esophageal clearance and stomach emptying which lead to long spontaneous contact of esophageal mucous membrane with acidic or alkali content of a stomach.

Involvement of adjacent systems and organs into a pathologic process determines diversity of clinical manifestation of a disease. Non-esophageal manifestations of 
GERD are commonly seen by cardiologists, ENT specialists, dentists [5-9]. Thus, GERD may rightly be called interdisciplinary problem.

Formation of GERD is determined by influence of many factors, but it is generally accepted that a main role is played by insufficiency of lower esophageal sphincter (LES), genesis of which is related to disorders of neurohumoral regulation. Results of investigations of pancreatic and gastrointestinal hormones in LES regulation in time of cardiospasm and GERD, carried out by means of protein and carbohydrate food loading tests showed role of vasoactive intestinal peptide (VIP) in a regulation of functional condition of LES [10].

Montreal definition of GERD created grounds for use of medicines decreasing acidity $[11,12]$. Main medicines, used in GERD treatment are proton pomp inhibitors (PPI). Effectiveness of different PPIs in treatment of GERD is studied, comparative analysis of use of different doses of medicines is also carried out. [13-15].

In case of inefficiency of medicines, surgical treatment of GERD is indicated. Open or laparascopic fundoplication was carried out at an early stage of anti-reflux surgical treatment development. Study of treatment results revealed up to $30 \%$ of various complications [16]. New methods are being elaborated and implemented with the aim of treatment results' improvement.

There is a significant growth in publications regarding studies of results of Transoral incisionless fundoplication (TIF), adiofrequency ablation (RFA) and anti-reflux mucosectomy (ARMS), laparoscopic magnetic sphincter augmentation, surgical ultrasound endostapler [17-20].

Despite success of pharmacological therapy, number of GERD patients does not demonstrate decreasing tendency, neither long-lasting effect of a therapy is seen which, in term, necessitates search of alternative non-medicine ways of treatment. For right now, named treatment methods are not widely used for treatment of gastroenterologic patients. Leading role among non-medicine methods of treatment is played by physical factors, affecting main elements of pathogenesis of diseases, capable of affecting functional disorders and pathological processes by influencing regulatory systems of organism. Main reason of restricted use of separate physical treatment methods is related to absence of presice efficiency estimation criteria based on principles of evidentiary physiotherapy [21]. There is no many investigations related to studies of effectiveness of natural and pre-formed physical factors in reflux-esophageal disease.

Use of SMT-phoresis (amplipuls-therapy) of chlorine iodine bromide brine in treatment of GERD patients contributed to disappearance or decrease of diarrhoeal manifestations and pain syndrome, as well as decrease of anxiety level [22].

Complex use of anti-ulcer medicines and SMT-phoresis of dalargin in rehabilitative treatment of GERD of Ist and IInd degree allowed to increase duration and stability of a remission in comparison with a period before treatment more than 3 times $(p<0,02)$, decreased total number of days of disability in 3,2 times $(\mathrm{p}<0,02)$., decreased medical load in 2,9 times $(\mathrm{p}<0,02)[23]$.

A course of lightly mineralized sodium-magnesium sulphate calcium-magnesium mineral water among patients with non-erosive gastroesophageal disease contributes to improvement of LES functional state with reliable decrease of refluxes' index, has an anti-inflammatory effect followed by disappearance and decrease of inflammatory changes of mucous membrane; effect is retained for six months [24].

Influence of low frequency magnetic therapy in a complex with local naphthalanum applications among GERD patients with concomitant bronchial asthma was investigated. Elaborated treatment course facilitated improvement of clinical manifestations of a disease, showed anti-inflammatory effect proved by decrease of eosinophils, fibrinogen, anti-inflammatory cytokines FHO- $\alpha$ and IL-1 $\beta$ in blood, normalization of physical features and microscopic characteristics of phlegm, improve of external breathing functional index [6].

Named studies reflected aspects related to clinical and functional state of esophagus and stomach; influence of physical factors on neurohumoral regulation of LES was not studied.

One of important points in treatment of GERD is impact on neurohumoral regulation of LES, disturbed motor skills of esophagus and stomach, factor of aggression - acid and alkali refluxes. It is known, that microwave electromagnetic field (MEF-therapy) impulses are being transmitted into central nervous system, reply reactions being formed are being further transmitted to executive organs by reflectory and neurohumoral ways which results in alterations of functional condition of gastrointestinal tract.

One of the leading positions among non-medicine treatment methods is held by acupuncture rooted in East and ancient times. Deep knowledge and systematic approach to an organism as a unique functional system allows wide use of named method in treatment of various diseases. Treatment approaches of acupuncture are reflected in fundamental writings of Eastern medicine, whereas description of pathogenetic mechanism of treatment effect in somatic diseases is an aim of modern medicine.

Dickman R and co-authors (2007) carried out randomized study related to acupuncture and omeprosole $(20 \mathrm{mg})$ therapy effect in complex treatment of non-erosive reflux patients. Results of studies showed that efficiency of a course of complex treatment is comparable with a double dose omeprosole treatment.

Analysis of results obtained allows to assume that acupuncture course normalized motor skills of esophagus and stomach [25], which also had been approved bu results of other studies [26, 27]. Studies named show efficiency of acupuncture in treatment of GERD patients, however, pathogenetic mechanisms of treatment mechanism in this group of patients are not disclosed.

Goal of this study is elaboration, scientific justification and clinical implementation of natural and preformed physical factors and acupuncture in treatment of patients with gastroesophageal reflux disease. 


\section{Materials and Investigation Methods}

Randomized placebo-controlled study included 137 patients with gastroesophageal reflux disease, 63 (46\%) men and $74(54 \%)$ women, at the age of 18 to 65 . Average age of patients was $31,1 \pm 1,08$ years, most of patients $(84,6 \%)$ were in productive working ability age of 21-50. Duration of diseases up to 5 years was registered in $98(71,5 \%)$ patients, from 6 to 10 years - among 23 patients $(16,7 \%)$.

Investigation included patients with no contraindications for physiotherapy. Patients with Barrett's esophagus, stricture of esophagus, esophagus ulcer have also been excluded from investigation.

Patients were divided into 3 groups:

Ist group - 40 GERD patients, including high-frequency electromagnetic field effect and general iodine bromine bathes.

IInd group - 67 GERD patients passing acupuncture treatment course.

Control group was comprised of 30 GERD patients, receiving placebo MEF therapy.

7 patients after plastics of esophagus, gastrostomy, those after burn stricture surgery of esophagus passed investigations after one procedure of microwave electromagnetic field (MEF) impact on gastric secretion.

Design of investigation assumes clinical investigation and verification of diagnosis, randomization and formation of a group of patients, control investigation with estimation of clinical symptoms, data of esophagogastroduodenoscopy, neurohumoral regulation of lower esophageal sphincter. 24-hour monitoring of $\mathrm{Ph}$ were held for verification of diagnosis and estimation of effectiveness of treatment.

Calculation of credibility of differences between groups was held by monofactor dispersive analysis with use of Student's T-criteria. Differences between two average values were considered credible at $\mathrm{p}<0,05$ value.

\section{Treatment Techniques}

Restorative treatment complex was established considering data found in literature regarding mechanism of effect of physical factors and clinical syndroms and functional disorders of digestive system and neurohumoral regulation revealed by us at admission of patients.

MEF therapy was supplied by apparatus "Volna-2" with power of 25-30 VT. Collar area was affected by rectangular emitter 35x16 sm, duration 8-10 minutes, course of treatment included 8-10 procedures, every other day; MEF therapy alternated with general iodine bromide bathes. Such location of physiotherapeutic procedures results in reflex excitation of vegetative apparatus and related neurological and endocrinological formations.

General iodine bromide bathes (chloride sodium based at concentration of $10 \mathrm{~g} / \mathrm{l}$ ) were administered at temperature of 36-37 C. Duration a bath was taken at was increased from 8-10 minutes at the beginning of treatment course to 12-15 minutes towards end of treatment course. Bathes were administered each other day, course consisted of 10-12 bathes. Main role in treatment effect of iodine bromide bathes is their effect on functional system of central nervous system directed to intensification of braking processes which is conditioned by direct affect of microelements - bromide. Iodine bromide bathes are prepared of natural or artificial mineral water. In nature ions of iodine and bromide are primarily found in chlorine sodium waters.

Accupuncture treatment course was held according to traditional methodics. Along with basic prescription acupuncture points considering individual manifestations of a diseases were used. Course of treatment included 10-12 procedures. Treatment was carried out along with diet. Care and functional rest of receptor apparatus of esophagus and stomach were primary in treatment; it was achieved by administering of blended food, not provocating secretion by sticking to frequent fractional meal regimen.

\section{Results of Treatment and Their Discussion}

Investigation of clinical manifestation of disease revealed following.

All patients complained of heartburn. 112 patients $(81,7 \%)$ had burp, $84(61,3 \%)$ - regurgitation. Pain under the xiphoid process appearing during meal was demonstrated by 46 $(33,6 \%)$ of patients, dysphagia of thick meal - by $25(18,3 \%)$, "sense of knot" behind sternum - $32(23,4 \%)$ of patients.

Non-esophageal manifestations most frequently included palpitation after a meal $-36(26,3 \%)$ of patients. Cardiac syndrome, so-called "non-cardiac chest pain" was registered among $16(11,7 \%)$ cases. Cough intensifying at night time was demonstrated by $23(16,7 \%)$ patients. Irritability and sleep disturbance was respectively registered among 52 (37,9\%) and $48(35 \%)$ patients.

All patients with pain behind sternum and disturbances of heart rhythm were examined by cardiologist. Patients with cough passed consultation of pulmonologist.

Endoscopic investigation revealed cardia failure; foamy mucus inside the gap of esophagus, as well as swelling and hyperemia of mucous membrane were registered. $21 \%$ of patients demonstrated single erosions of lower third of esophagus.

24-hour monitoring of $\mathrm{pH}$ revealed acid refluxes among $79 \%$ patients and alkaline ones among $21 \%$.

Definition of a neurotransmitter taking part in regulation of a functional state of Lower Esophageal Sphincter (LES) vasoactive intestinal peptide (VIP), revealed credible elevation of its level in blood serum of GERD patients up to $36,5 \pm 1,01 \mathrm{pg} / \mathrm{ml}$ when the same data for healthy person is $29,85 \pm 1,01 \mathrm{pq} / \mathrm{ml}, \mathrm{p}<0,05$.

Thus, GERD patients along with demonstrating esophageal and extra-esophageal symptoms, also experience alterations in functional state of esophagus, elevation of a level of vasoactive intestinal peptide in blood.

Rationale for choice of physiotherapy impact zone was 
provided by results of investigations of single procedures of MEF affecting gastric secretion. Fractional investigation of gastric acid does not exclude fact of duodenal secretion getting into stomach as a result of aspiration. Investigation of gastric acid freely flowing from gastrostomy was approaching conditions of physiological experiment.

Studies were performed in the morning, on an empty stomach. During 45 minutes (every 15 minutes) patients were collecting portions of gastric acid flowing from gastrostomy. Then epigastric area was exposed to MEF with capacity of 25 $-30 \mathrm{~W}$, after which fractional study of gastric acid had been continued. Increase of volume of gastric acid is registered from $44,6 \mathrm{ml}$ to $58,8 \mathrm{ml}$, which makes $31,8 \%$; also, volume of free hydrochloric acid in gastric acid is elevated after exposure of gastric area to MEF.

Studies of gastric secretion among the same patients including exposure of collar area to MEF with capacity of 25-30 W revealed following. Patients with gastrostomy demonstrated decrease of gastric acid volume on average from $42,2 \%$ to $30,9 \%$, which means $27,12 \%$. Acidity of gastric acid has not been substantially changed.

Results obtained show that single MEF exposures with capacity of 25-30 W directed on collar area decrease volume of gastric secretion, which may indirectly point to oppression of gastric secretion as well as stimulation of gastric evacuation function; these factors are both favourable for GERD patients. Results of investigation justify choice of collar area exposure to MEF therapy in treatment of GERD patients.

Treatment course resulted in improvement of general condition of dominant number of patients, elimination of sleeping disorders, favourable changes in subjective and objective manifestations of disease also were registered. Heart burn complaints disappeared in $75 \%$ of patients of Ist group, and $83,6 \%$ of IInd group. Burp was not more registered among $53 \%$ of patients of Ist group, $61,5 \%$ of IInd group. Pains under xiphoid, intensifying at meal, disappeared among $78,6 \%$ of patients of Ist group, all the patients of IInd group. Regurgitation was not registered among $75 \%$ of Ist group, $97 \%$ of IInd group. Disphagia after treatment was not registered neither among patients of Ist group no among those in IInd group. Palpitation disappeared among all patients of Ist group and $90 \%$ of patients of IInd group. "Non cardiac chest pain" was not registered in either group of patients. Cough intensifying at night time was eliminated among $50 \%$ of patients of Ist group and $75 \%$ of IInd group.

$21,4 \%$ of patients who passed 5 procedures of MEF and iodine bromine bathes had complaints of pain under xiphoid, medicines were prescribed in relation with that. One of patients $(2,5 \%)$ demonstrated deterioration after $\mathrm{MEF}$ procedures, physiotherapy was abolished, medicines were prescribed (PPIs and prokinetics).

Results of investigation of control group patients showed that $40 \%$ of patients did not have heartburn complaints, $30 \%$ of patients demonstrated decrease of burps, $30 \%$ did not display any dynamics of main complaints.

Functional condition of LES was studied by ph-monitoring of esophagus. Studies were held among 22 patients of Ist group. Number of refluxes were registered from $\mathrm{ph}<42$ hours before a procedure, during MEF exposure on collar area and 2 hours later after a procedure.

Number of refluxes of $\mathrm{ph}<4$ in one hour in laying position before procedure was on an average 4,3. Single refluxes were registered during MEF exposure on collar area held at position when patient was laying on his stomach among $27 \%$ of patients. After MEF procedures number of refluxes with $\mathrm{ph}<4$ has decreased almost three times (chart 1).

\section{Ph-diagram of patient Sh.}

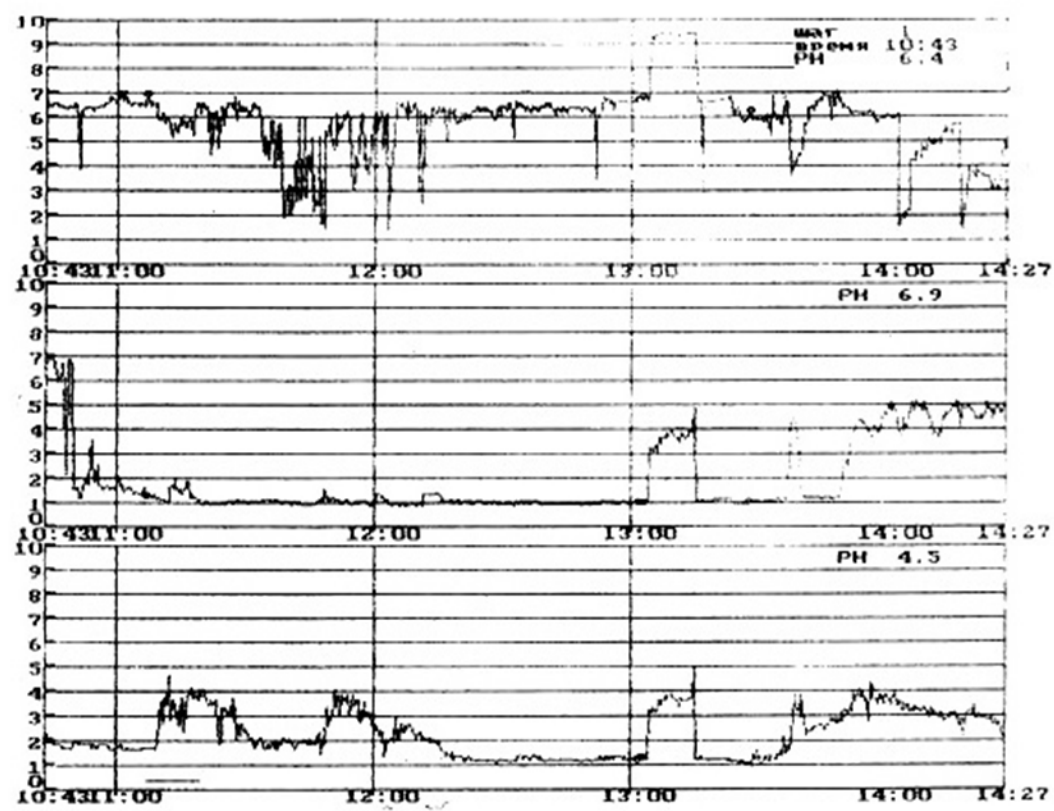

1.1

1.1-ezophagus, 1.2 - corpus of stomach, 1.3 - antrum of stomach

Figure 1. 12:15-12:25 MEF-therapy applied on collar area. 
Results of investigation show that single procedures of MEF with capacity of $25 \mathrm{~W}$ applied to collar area increased LES tone, decrease of number of transitory relaxations of LES are evidences of that. No substantial dynamics are seen in ph of gastric acid after application of MEF on to collar area.

Study of functional condition of LES among 43 patients of
IInd group according to esophagus ph-monitoring data showed decrease of number of refluxes with $\mathrm{ph}<4$ from 4,8 to 0,7 in an hour after acupuncture, which testifies increase of LES tone. (chart 2). Decrease of intensity of acid formation from $1,42 \pm 0,03$ to $1,64 \pm 0,03(\mathrm{p}<0,05)$ was registered only among patients receiving acupuncture.

Ph-diagram of patient $\mathrm{K}$.
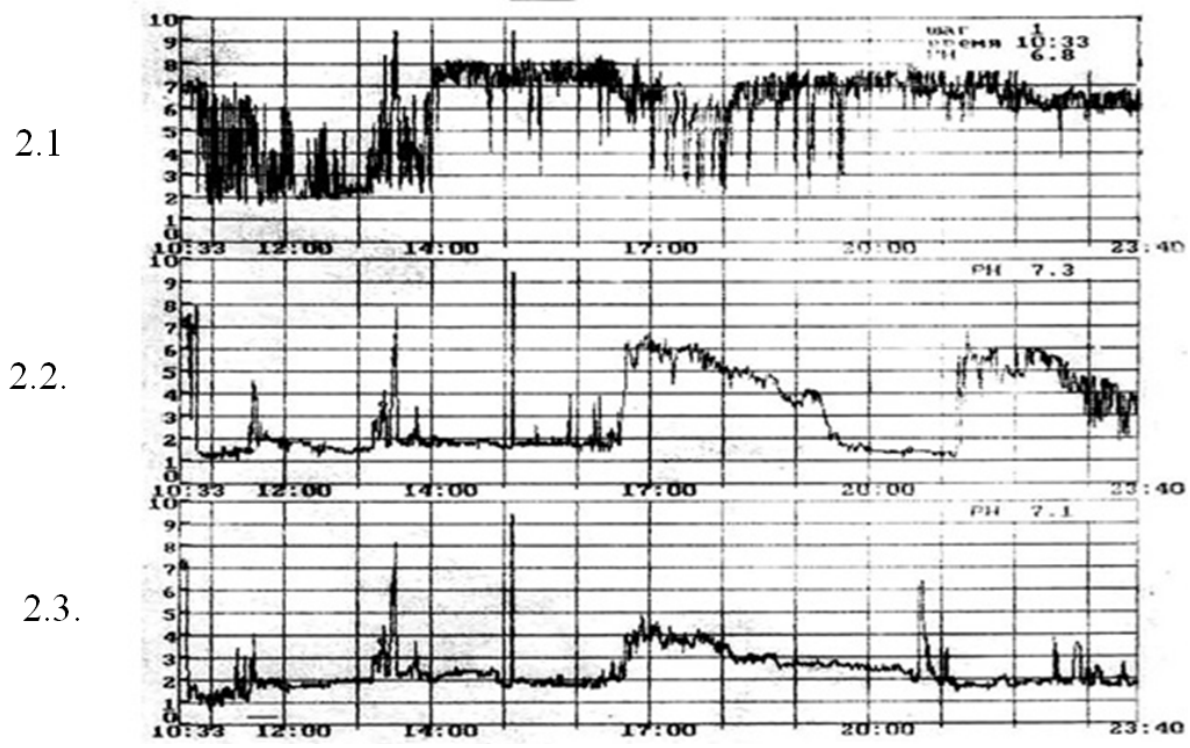

2.1-ezophagus, 2.2 - corpus of stomach, 2.3 - antrum of stomach

Figure 2. 14:00-14:30-acupuncture procedure.

Study of VIP concentration in dynamics was carried out among 56 GERD patients in age group from 20 to 40 with no concomitant disease.

Patients of Ist group demonstrated decrease in elevated level of VIP in blood from $36,9 \pm 1,4 \mathrm{pg} / \mathrm{ml}$ to $30,7 \pm 1,48 \mathrm{pg} / \mathrm{ml}$ $(\mathrm{p}<0,05)$ after treatment and from $34,3 \pm 1,4 \mathrm{pg} / \mathrm{ml}$ to $24,06 \pm 1,16 \mathrm{pg} / \mathrm{ml}(\mathrm{p}<0,01)$ after acupuncture. No substantial alteration in VIP level is registered in control group.

Decrease of VIP may be an evidence of LES function improvement, and, as a consequence, decrease or total elimination of gastric reflux into an esophagus.

Results obtained show that acupuncture procedure applied to corporal points according to brake method resulted in increase of tone of lower esophageal sphincter, decrease of number of transitory relaxations of lower esophageal sphincter. Accupuncture course applied according to this method also contributed to credible ph elevation of basal gastric acid. Thus, acupuncture affected different links of GERD pathogenesis. Affecting functional condition of LES on the one hand, it also influenced acid-peptic aggression factor on the other hand. There are studies in literature related to investigation of pressure in pyloric sphincter and gastric motility when affecting $\mathrm{E}_{36}$ point. L. W. Qian and Y. P. Lin [28]. have revealed double effect when influencing $\mathrm{E}_{36}$ point: increase at hypofunction and decrease at hyperfunction of pyloric sphincter. Results obtained from GERD patients reveal an affect of acupuncture which has not been recognized before - influence on fuctional condition of LES being manifested in improve of obturator mechanism of cardia, data of endoscopic investigation confirmes it. Restoration of obturator mechanism of cardia prevents throw of gastric content into an esophagus.

It is known, that a brain, along with including well-learned cholinergic and aminergic neurons, also contains an extensive peptidergic system. Most of peptides are concentrated in brain stem, hypothalamus and limbic parts of brain. Nerve endings containing secretion similar with secretory granules of peptidergic nerves of neuro pituitary gland. These non-adrenergic and non-cholinergic nerves of vegetative nervous system partly comprise of nerves containing VIP and play sufficient role in pathogenesis of gastrointestinal diseases, accompanied by disorders of peristalsis and secretion. Secretion of VIP is being inhibited by opioid neurons. Analgetic effect of acupuncture is related to secretion of opioid peptides of $\beta$-endorphines. Decrease of VIP secretion among GERD patients who passed acupuncture treatment is most probably related to increase of $\beta$-endorphines' production.

Study of distant results among 52 GERD patients 6 months after treatment revealed following. $70 \%$ of patients who had been receiving MEF therapy and general bromide bathes for 6 months did not have heartburn complaint. Relapse of heartburn complaints was registered among $30 \%$ of patients. In a group of patients receiving acupuncture $78 \%$ 
demonstrated positive results 6 months after a treatment course, relapse of disease was registered in $22 \%$ of patients.

\section{Conclusion}

To summarize abovementioned, it can be concluded that treatment methods including MEF therapy and general bromide bathes, acupuncture, are pathogenetically justified and effective for therapy of GERD patiens.

Higher therapeutic effect, ability to affect different links of GERD pathogenesis, no side effects and availability of choice of different points depending on individual specifics of a patient considering concomitant pathology allows to give preferences in treatment course of GERD I and II degree patients (Savary-Miller classification) to acupuncture.

Administration of MEF therapy in a complex with bromide bathes is prescribed to GERD patients with esophagitis of 0 degree who does not contraindications to physiotherapy. GERD patients with esophagitis of I degree may be prescribed MEF therapy with general bromide bathes and corresponding medicines.

In light of modern approaches to treatment methods of common diseases personalization principles is an area of growing importance in medicine in nowadays. From that position continued investigations and studies of pathogenetically justified treatment methods of GERD patients along with results of previous investigations allows to systematize and implement personalization principles in treatment of this category of patients.

\section{References}

[1] Tsimmerman YaS, Vologzhanina LG. Gastroesophageal reflux disease: pathogenesis, clinical presentation, diagnosis and treatment. Klinicheskaya meditsina. 2005; 83 (9): 16-24. (In Russ.).

[2] Vaezi MF, ed. Diagnosis and Treatment of Gastroesophageal Reflux Disease. Springer International Publishing Switzerland. 2016. 165 p

[3] Yadlapati R, Tye M, Keefer L, et al. Psychosocial distress and quality of life impairment are associated with symptom severity in PPI non-responders with normal impedance- $\mathrm{pH}$ profiles. Am J Gastroenterol. 2018; 113 (1): 31-38. [PubMed: 28895583]

[4] Ravindran A, Iyer PG. Gastroesophageal Reflux Disease and Complications. In: Pitchumoni CS, Dharmarajan TS, eds. Geriatric Gastroenterology. Springer Nature Switzerland AG. 2020: 1-17.

[5] Maev IV, Kazyulin A. N., Yurenev G. L. Cardiac syndrome under gastroesophageal reflux disease: manifestations, incidence rate, causes and remedies. Effektivnaya farmakoterapiya. 2014; (25): 8-17. (In Russ.).

[6] Badalov NG, Efendieva MT, Golubeva VV. The influence of magnetic therapy and naftalan treatment on the clinical course of gastroesophageal reflux disease with concomitant bronchial asthma. Fizioterapiya, bal'neologiya i reabilitatsiya. 2017; (1): 25-31. (In Russ.).
[7] Zalvan CN, ed. Laryngopharyngeal and Gastroesophageal Reflux. A Comprehensive Guide to Diagnosis, Treatment, and Diet-Based Approaches. Springer Nature Switzerland AG. 2020. 487p.

[8] Yadlapati R, Pandolfino JE, Lidder AK, et al. Oropharyngeal $\mathrm{pH}$ testing does not predict response to poton-pump inhibitor therapy in patients with laryngeal symptoms. Am J Gastroenterol. 2016; 111 (11): 1517-1524. [PubMed: 27091320]

[9] Marsicano JA, de Moura-Grec PG, Bonato RC, Sales-Peres Mde C, Sales-Peres A, Sales-Peres SH. Gastroesophageal reflux, dental erosion, and halitosis in epidemiological surveys: a systematic review. Eur J Gastroenterol Hepatol. 2013; 25 (2): 135-41.

[10] Poroikova MV, Efendieva MT, Vinnitskii LI. Regulation of the functional status of the lower esophageal sphincter with gastrointestinal hormones in cardiospasm and reflux esophagitis. Vestnik Rossiiskoi akademii meditsinskikh nauk. 2002; (7): 23-8 (In Russ.).

[11] Hungin APS, Molloy-Bland M, Scarpignato C. Revisiting Montreal: new insights into symptoms and their causes, and implications for the future of GERD. Am J Gastroenterol. 2019; 114: 414-421. [PubMed: 30323266]

[12] Horgan S, Fuchs K-H, eds. Management of Gastroesophageal Reflux Disease. Surgical and Therapeutic Innovations. Springer Nature Switzerland AG. 2020. 212p.

[13] Yadlapati R, Vaezi MF, Vela MF, et al. Management options for patients with GERD and persistent symptoms on proton pump inhibitors: recommendations from an Expert Panel. Am J Gastroenterol. 2018; 113 (7): 980-986. [Pubmed: 29686276]

[14] Miwa H, Igarashi A, Teng L, et al. Systematic review with network meta-analysis: indirect comparison of the efficacy of vonoprazan and proton-pump inhibitors for maintenance treatment of gastroesophageal reflux disease. J Gastroenterol. 2019; 54: 718-729. [PubMed: 30919071]

[15] Miraglia C, Russo M, Barchi A. T01.02.19. Is it possible to withdraw PPIS therapy in GERD patients? A prospective study on 216 patients using a second generation barrier drug. Abstracts of the 26th National Congress of Digestive Diseases. Dig Liver Dis. 2020; 52S2: S1-S203.

[16] Yadlapati R, Hungness ES, Pandolfino JE. Complications of antireflux surgery. Am J Gastroenterol. 2018; 113 (8): 1137-1147. [PubMed: 29899438]

[17] Testoni PA, Testoni SGG, Mazzoleni G, Fanti L. Transoral Incisionless Fundoplication (TIF) for Treatment of Gastroesophageal Reflux Disease. In: Wagh MS, Wani SB, eds. Gastrointestinal Interventional Endoscopy. Springer Nature Switzerland AG. 2020: 325-338.

[18] Chang KJ, Beel R. Transoral incisionless fundoplication. Gastrointest Endosc Clin N Am. 2020; 30 (2): 267-289. [PubMed: 32146946]

[19] Brimhall B, Maydeo A, Wagh MS, Hammad H. Radiofrequency Ablation (RFA) and Anti-Reflux MucoSectomy (ARMS) for Gastroesophageal Reflux Disease. In: Wagh MS, Wani SB, eds. Gastrointestinal Interventional Endoscopy. Springer Nature Switzerland AG. 2020: 339-344. 
[20] Bell R, Lipham J, Louie B, et al. Laparoscopic magnetic sphincter augmentation versus double-dose proton pump inhibitors for management of moderate-to-severe regurgitation in GERD: a randomized controlled trial. Gastrointest Endosc. 2019; 89 (1): 14-22. e1. [PubMed: 30031018]

[21] Ponomarenko G. N., Zolotareva T. A. Fizicheskie metodi v gastroenterologii. Saint-Petersburg; 2004. (In Russ.).

[22] Korepanov AM, Mikhailova MD. The application of spa and resort factors for the treatment of gastroesophageal reflux disease. Voprosy kurortologii, fizioterapii $i$ lechebnoi fizicheskoi kul'tury. 2011; (2): 27-30. (In Russ.).

[23] Efimenko NV, Ebzeev AKh, Chalaya EN. SMT-forez dalalgina pri gastroezofagealnoi reflyuksnoi bolezni. Gastroenterologiya Sankt-Peterburga. 2012; (2-3): 31. (In Russ.).

[24] Usmanov FF, Gil'mutdinov AR, Kunafin AF, Gil'mutdinova LT, Yamaletdinov KS. Potable mineral water in the treatment of patients with gastroesophageal reflux disease. Meditsinskii vestnik Bashkortostana. 2013; 8 (6): 135-7. (In Russ.).

[25] Dickman R, Schiff E, Holland A, Wright C, Sarela SR, Han B, Fass R. Clinical trial: acupuncture vs. doubling the proton pump inhibitor dose in refractory heartburn. Aliment Pharmacol Ther. 2007; $26 \quad$ (10): 1333-44. https://doi.org/10.1111/j.1365-2036.2007.03520.x.

[26] Xu S, Hou X, Zha H, Gao Z, Zhang Y, Chen JD. Electroacupuncture accelerates solid gastric emptying in patients with functional dyspepsia. Gastroenterology. 2004; 126 (12): T1163.

[27] Chang X, Yan J, Yi S, Lin Y, Yang R. The affects of acupuncture at sibai and neiting acupoints on gastric peristalsis. $J$ Tradit Chin Med. 2001; 21 (4): 286-8.

[28] Qian L. W., Lin Y. P. Effect of EAP at zusanli (ST 36) point in regulating the pylorus peristaltic function//Chung Kuo Chung Hsi J Chieh Ho Tsa Chin Jun.- 1993.-13 (6): 336-339. 